\title{
Excellent Resource Sharing Course Construction on Aquatic Biostatistics
}

\author{
Jing Zhang ${ }^{1, a}$, Yunrong Yan ${ }^{2, b}$, Zhongliang Wang ${ }^{3, c}$, Xuefeng Wang ${ }^{4, c}$ and \\ Chunyan Shen ${ }^{5, \mathrm{c}}$ \\ ${ }^{1-5}$ Fisheries College, Guangdong Ocean University, Zhanjiang, Guangdong, China \\ azjouzj@126.com, byanyr@gdou.edu.cn, Wangzl@gdou.edu.cn, ${ }^{\mathrm{a}}$ Wangxf@gdou.edu.cn, \\ eShency@gdou.edu.cn
}

Keywords: aquatic; biostatistics; excellent resource sharing course

Abstract. According to the course construction and teaching reform of aquatic professional courses, excellent resource sharing course construction on aquatic biostatistics is elaborated on three aspects: course construction target, construction train of thought and construction content.

\section{Introduction}

There are three majors namely Aquaculture, Marine Fishery Science and Technology and Marine Science in Fisheries College, Guangdong Ocean University. As an important applied mathematics, biostatistics has always been the professional basic course, and has been widely used in graduation experiment design and thesis writing over the years. It plays an important role in scientific research on aquatic science. Since the 21 st century, with the development of the society and the progress of science, the focus on higher education training objective has been turned from knowledge instruction to ability cultivating; and the talents that cultured have been turned from knowledge inheriting and using to knowledge development and innovation [1]. The transition of talents training objective sets newer and higher demands on college course teaching. At the same time, with the success on master and doctor's authorizations of Fisheries College, the course construction and teaching reform of aquatic professional courses are imperative. The construction of discipline basic courses was highly thought by Fisheries College and the "Aquatic Biostatistics" was proposed as a college limited course in the revised personnel cultivating program in 2013. The course was approved as one of the outstanding classroom teaching established projects in 2013 and excellent resource sharing course in 2014. In this paper, the excellent resource sharing course construction train of thought on Aquatic Biostatistics is proposed combining with the construction of excellence classroom and specialty course.

\section{Construction Target}

Under the new situation and combining with the professional background, how to improve the course teaching system, reform teaching content and method by the new way and new method is tried to explore through the construction of this course. The open teaching mode combining with theory and practice is adopted to improve the teaching effect of this course and the students' ability to analyze and solve problems by deepening theoretical knowledge, exploiting students' thought, cultivating thought methods of scientific research, and improving innovative consciousness and ability etc. At the same time, a course website is established to provide a platform for students to study, communication and knowledge expansion after class.

\section{Construction Train of Thought}

Highlighting Oceanic and Aquatic Characteristics. According to the characteristics of talents training and courses system of different majors in Fisheries College, the oceanic and aquatic characteristics should be highlighted for course application on experiment design and data analysis and processing. 
Strengthening Course Construction. There are 48 class hours in Aquatic Biostatistics, and the proportion is 3 to 1 in theory and experiment. There are 2-3 teachers in this course and a teaching echelon should be established leading by a chief teacher who should be a professor and a doctor. The teaching staff construction should be strengthened by using research to guide teaching, using teaching to assist research, and learning from each other in mutual emulation among teachers. This course and its further follow-up should be opened during three study stages of undergraduate, master and doctor to form a complete chain of statistical learning, and could be really used in teaching and scientific research in Fisheries College.

Optimizing Teaching Content. Great attention must be paid to professional background and practicability. The teacher should explain the profound experimental design of basic theory and principle in a simple way by using oceanic and aquatic organisms as objects, and guide students to learn and master the principle and method of how to obtain, analyze and infer the data reasonably and effectively. Make full use of the hardware and software resources provided by the university to make multimedia courseware and collect statistics learning materials.

Reforming Teaching Methods. Aquatic biology is an experimental subject, and many biological phenomena and principles are found in the experiment and verified by experiments. So the stand or fall of experimental design directly affects the results of the analysis and conclusion of correct, reliable or not. The combination of theory and practice is adopted as an important means of teaching.

\section{Construction Contents}

Theory Teaching. (1) Starting from the background of the major, the connections between abstract theory and specific problems that students familiar with should be established to enable students to master all kinds of test model assumptions and their applications through the comparison research. (2) An exploratory and interactive teaching method should be adopted to inspire students' thought, broaden students' way of thinking and guide students to think problems using the way of scientific research. Make sure to give full priority to students "learning" instead of teacher "speaking", and to improve students' ability to analyze and solve problems by organically combining the teacher's teaching with the students' self-study, discussion and research. (3) Extracurricular reading and class review methods should be adopted to train students' ability of accessing knowledge independently, and to lay the foundation for students' life-long learning and innovation. (4) Multimedia courseware should be carefully designed to show the dynamic analysis process of the data according to the characteristics of this course besides the graphic and vivid characteristics that general multimedia courseware possesses. As far as possible to make courseware integrating teaching, scientific, artistic and technical to stimulate students' interest in learning to improve teaching efficiency.

Practice Teaching. Three levels of practice teaching include: (1) Basic practice made by experimental design is used to deepen students' understanding of the basic principle. (2) Comprehensive and designing practice proposed by teachers is used to test students' ability of designing and analyzing. (3) Research practice made by students themselves is used to inspire students' ability of self topic selecting, experiment designing and problem analyzing and inferring.

Course Website Construction. The contents include:

Electronic Teaching Plan. Make sure that the plan should has clear contents, outstanding emphasis and difficult points, and detailed annotation for knowledge points, so that students can clearly understand and grasp the teaching contents.

Question Bank. Compile and design a set of matched problems for students to self-test after class, and a detailed solving process is attached for students to analyze and study.

Learning Materials. A series of learning materials including classical statistic stories, explanation for statistic special topic and other statistic learning websites etc. should be widely collected to enrich students' view. 
Experiment Teaching Demonstration System. In order to mach the experimental teaching to theoretical teaching, teaching demonstrations are recorded for students to learn how to operate the statistic software to master them quickly.

Microlecture Video. The traditional teaching video is long for about 45 minutes and it is a repeatability of the whole course. It takes students so much time to watch it and makes students feel tired and lose interest in learning therefore. Microlecture method is adopted to record a knowledge point with 5 to 15 minutes long, and it takes students a little time to review and preview the emphasis they are interested in.

Assessment Method. Assessment is an important means to urge students to review, consolidate knowledge and to check the teaching effect. It takes students too much time to recite calculation formula and perform mathematical calculation in traditional written examination. It cannot completely and accurately inspect students' mastery and application situation of various statistical analysis methods. A reform on assessment method is conducted that computer examination is added to traditional written examination. In the written examination, it focuses on the understanding of the concepts and the application conditions, there is no need to recite items, remember a lot of formulas, and perform complex calculations. In the computer examination, it requires students to apply their statistic knowledge to choose a proper statistic command to calculate, and to analyze and explain the statistic results. By that way, it not only solves students' learning burden, but also helps students be interest in this applicable mathematics, and it really achieves the training target of this course.

\section{Acknowledgements}

This work was financially supported by the Project of Enhancing School with Innovation of Guangdong Ocean University, the Project of Undergraduate Education Quality and Reform of Guangdong Province(GDOU2015041802), the Project of Graduate Students Model Course Cultivation of Guangdong Ocean University, the Project of Outstanding Classroom Teaching of Guangdong Ocean University, the Project of Educational Reform of Guangdong Ocean University (XJG201242) and the Aquatic Science and Technology Experimental Teaching Center.

\section{References}

[1] P.Y. Li, Z.J. Sun, in: Educational Reform Ideas on Field Trial with Biostatistics in Pratacultural Science Profession, Animal Husbandry and Veterinary of Heilongjiang Province (2014), p. 186-188 